\title{
La Escisión: sus aspectos societarios y tributarios
}

Jorge Luis Ramírez ZegarRa

Abogado por la Universidad de Lima. Profesor de Derecho Comercial en la Universidad de Lima.

\section{Luis Felipe Velarde Koechlin}

Abogado por la Universidad de Lima. Máster en Derecho Empresarial por la Universidad de Lima.

SUMARIO:

I. Antecedente y conceptos.

II. La escisión: una manera práctica de comprenderla.

III. Razones para realizar una escisión.

IV. Formas de la escisión.

V. Concepto de bloque patrimonial y su integración patrimonial.

VI. Implicancias tributarias de la escisión:

1. Del Impuesto a la Renta;

2. Del Impuesto General a la Ventas.

VII. Otras consideraciones importantes sobre la escisión:

1. El procedimiento de escisión;

2. Diferencias de la escisión con otras instituciones jurídicas reguladas en la Ley. 


\section{ANTECEDENTES Y CONCEPTO}

La escisión en sí es una institución jurídica, cuyo antecedente legal en materia societaria se remonta a la Ley de Sociedades de Francia de 1966. Sin embargo, sus antecedentes legales para su tratamiento legislativo no se centran propiamente en el Derecho Societario Francés, sino en normas fiscales vinculadas al Derecho Tributario. Así ocurrió no sólo en Francia, sino en otros países como en los Estados Unidos de Norteamérica, Argentina y España.

Es más, el doctor Enrique Elías Laroza refiere que "a partir de las décadas de los cuarenta y de los cincuenta, el legislador francés, por razones económicas, fue extendiendo las ventajas tributarias que existían para las fusiones a favor de ciertas operaciones de división o desmembración de empresas, lo que hizo cada vez más necesaria la dación de una normativa estrictamente necesaria de las escisiones, proceso que culminó en la citada Ley de 1966"1.

En la legislación peruana, solamente en el régimen tributario, encontramos ciertos antecedentes de regulación de la división de sociedades, aunque las características para estos casos no son aquellas que la doctrina y legislación mercantil consideraban propias y fundamentales para la escisión societaria, haciendo presente que mediante una serie de procedimientos $y$ la aplicación de diferentes figuras jurídicas era factible llegar de manera compleja a la misma situación alcanzada mediante la escisión societaria.

Sin embargo, el desarrollo de la actividad económica originó que las empresas y sociedades se adecuen a las condiciones de mercado y sean competitivas, pues de lo contrario podrían tender a quedar fuera del mismo. Con esa premisa, la Ley General de Sociedades vigente en nuestro país (Ley 26887), promulgada el 9 de diciembre de 1997 y que rige desde el 1 de enero de 1998, trata el tema de la reorganización de sociedades, no sólo en el sentido de replantear la forma jurídica de la sociedad, sino concentrando o desagrupando los patrimonios para asignarlos a otras sociedades. Tal es el caso de la fusión y la escisión, tema este último que trataremos en el presente artículo.

En cuanto al concepto de "escisión", el tratadista argentino Julio Otaegui señala que "una escisión consiste en el desdoblamiento de una persona jurídica en nuevas personas jurídicas, pudiendo subsistir o extinguirse la persona jurídica inicial, según se trate de una excorporación o de una división" ${ }^{\prime 2}$. Al propósito, se habla de sociedad excorporante cuando esta transfiere sólo una parte de su patrimonio a favor de una sociedad excorporada o beneficiaria. El tratadista español Fernando Cerdá Albero, al referirse a la sociedad anónima, sostiene que "strictu sensu, la escisión de una sociedad anónima es la división de su patrimonio social en dos o más partes, a fin de traspasar en bloque una, varias o la totalidad de estas partes resultantes de la división a una o varias sociedades preexistentes o constituida a raíz de esta operación, recibiendo los accionistas de la sociedad escindida acciones o participaciones de $\mathrm{la} / \mathrm{s}$ sociedad/es beneficiaria/s en contraprestación a esta aportación"13.

La doctora Rossana Sala Estremadoyro, en su afán de buscar un concepto claro de cómo podría ser definida la escisión dentro de nuestro ordenamiento nacional, lo hace señalando que la escisión es "una figura jurídica por la cual una sociedad separa una parte o divide la totalidad de su patrimonio para transferirlo a una o varias sociedades preexistentes o que han de constituirse, atribuyendo directamente a los accionistas o participacionistas de la sociedad escindente, como contraprestación a dicho aporte, acciones o participaciones de la o las sociedades escisionarias, convirtiéndose por lo menos uno de los socios

1. ELÍAS LAROZA, Enrique. Derecho Societario Peruano. La Ley General de Sociedades del Perú. Obra completa. Trujillo, Editora Normas Legales, 2003. pp. 783-784.

2. OTAEGUI, Julio. Fusión y escisión de sociedades comerciales. Buenos Aires, Abaco, 1981. p. 249.

3. CERDA ALBERO, Fernando. Escisión de la sociedad anónima. Valencia, Tirant Lo Blanch, 1993. p. 29. 
de la o las sociedades escindentes en socio de la o las sociedades beneficiarias" ${ }^{\prime \prime}$.

La escisión es, pues, regulada por primera vez en nuestra Ley General de Sociedades vigente, en adelante LGS, desde el artículo 367 hasta inclusive el artículo 390.

La propia LGS la define en su artículo 367, señalando que por la escisión una sociedad fracciona su patrimonio en dos (2) o más bloques para transferirlos íntegramente a otras sociedades o para conservar uno (1) de ellos; siendo importante en la escisión el fraccionamiento del patrimonio de la sociedad que se escinde, que, como es de verse, puede ser total o parcial, en tanto dicho fraccionamiento patrimonial sea en bloques patrimoniales.

\section{LA ESCISIÓN: UNA MANERA PRÁCTICA DE COMPRENDERLA}

NOTA: Debemos precisar que los ejemplos y los cuadros a exponer en el presente capítulo II son meramente para fines referenciales. Es importante considerar que la contabilidad de una sociedad puede contener mayores elementos; empero, optamos por simplificar estos para facilitar su comprensión.

Sin perjuicio de la vital importancia que significa comprender el aspecto legal-societario de la escisión, consideramos que una óptica contable nos podría ayudar a entender cuál es el efecto que genera una escisión en la organización de una (1) o más sociedades.

Al respecto, debido a que las sociedades son constituidas con fines de lucro (es decir, para que los socios o accionistas se beneficien con sus utilidades o ganancias), es importante comprender que el balance general de una sociedad estaría compuesto, entre otros elementos que contiene una amplia contabilidad, por la fórmula de "activo = pasivo + patrimonio neto", cuyo ejemplo graficamos a pie de página.

En efecto, como se puede apreciar, los activos de la sociedad son todos los derechos y propiedades que esta tiene a su nombre como persona jurídica; contrario es el caso de los pasivos, que son todas las obligaciones y deudas que tiene la sociedad con terceros, y el patrimonio neto, que vendría a ser, en buena cuenta, las deudas que tiene la sociedad a favor de sus accionistas que aportaron un capital social y esperan obtener utilidades (resultados del ejercicio).

Ahora bien, al margen de los requisitos y trámites legales, al momento realizar una escisión se extrae de una sociedad (escindida o transferente) un conjunto de activos, pasivos y patrimonio neto del total del balance general, que mantenga la simetría de "activo = pasivo + patrimonio neto", para destinarlo a otra sociedad o crear una nueva (beneficiaria).

\begin{tabular}{|c|c|c|c|}
\hline \multicolumn{4}{|c|}{ Cuadro No. 1} \\
\hline \multicolumn{2}{|c|}{ Activo } & \multicolumn{2}{|l|}{ Pasivo } \\
\hline Caja y bancos & S/. 100.00 & Cuentas por pagar & S/. 200.00 \\
\hline Cuentas por cobrar & S/. $\quad 70.00$ & Remuneraciones por pagar & 40.00 \\
\hline Maquinarias & S/. $\quad 500.00$ & & \\
\hline \multirow[t]{5}{*}{ Total activo } & S/. $\quad 670.00$ & Total pasivo & S/. $\quad 240.00$ \\
\hline & & \multicolumn{2}{|c|}{ Patrimonio neto } \\
\hline & & Capital social & S/. $\quad 300.00$ \\
\hline & & Resultados del ejercicio & S/. $\quad 130.00$ \\
\hline & & Total patrimonio neto & S/. $\quad 430.00$ \\
\hline Total activo: & S/. $\quad 670.00$ & Total pasivo + patrimon & S/. $\quad 670.00$ \\
\hline
\end{tabular}

4. SALA ESTREMADOYRO, Rossana. Escisión de sociedades en materia societaria. Lima. Tesis para optar grado de bachiller, 1988. p. 359. 
A manera de ejemplo, la sociedad "AAA" es una empresa destinada al giro de fabricación de calzado y accesorios de cuero para venderlo a distribuidores mayoristas, que cuenta con el balance general detallado en el cuadro No. 1 . No obstante ello, los accionistas de la sociedad " $A A A^{\prime}$ " desean incursionar en la venta de sus productos al público en general.

Pese a que se trata de un mismo producto (calzados), los accionistas de la empresa "AAA" son conscientes que la venta al público en general tiene otro tipo de administración y operatividad muy distinta a la fabricación, como por ejemplo: contar con personal de ventas que ofrezca una buena atención al público, contar con un sistema de ventas y de almacén distinto al del rubro de fabricación, celebrar contratos de alquiler para contar con establecimientos en centros comerciales, entre otros.

En tal sentido, y continuando con el ejemplo, los accionistas desean acogerse a un régimen de la Micro y Pequeña Empresa (MYPE), el cual permite, entre otros beneficios, un menor pago de impuestos de manera mensual y un régimen que disminuye sus costos laborales, para minimizar los riesgos en el nuevo proyecto de venta al público en general. Entre los diversos requisitos se dispone que, para acogerse al régimen, una microempresa debe contar con un máximo con diez (10) trabajadores.

Es por ello que, mediante una Junta General de Accionistas, se acordó escindir un bloque patrimonial de la sociedad "AAA" (escindida o transferente) que sea de utilidad para constituir la nueva sociedad "BBB" (beneficiaria) que se dedicará a la venta de calzado al público en general. Dicho bloque patrimonial comprende los siguientes elementos como se ve en el cuadro de la parte inferior

Como se puede apreciar en el cuadro No. 2, el bloque patrimonio escindido constituye un conjunto de activos, pasivos y patrimonio neto que debe mantener una simetría de derechos y obligaciones entre sí, y abarca los elementos necesarios para que la nueva sociedad beneficiaria "BBB" pueda iniciar su actividad, mientras que la sociedad transferente "AAA" mantiene un bloque patrimonio remanente de $S / .600 .00$, con motivo de la escisión del bloque patrimonial escindido (S/. $670.00-S / .70 .00)$

Es por ello que se habla de un "bloque patrimonial", el cual es, en sentido coloquial, el referido conjunto de activos, pasivos y patrimonio neto destinado a la sociedad.

\section{RAZONES PARA REALIZAR UNA ESCISIÓN}

Para poder comprender, también, el por qué muchos negocios optan por realizar una escisión de empresas, dentro de las causas o fines que inspiran esta pueden considerarse, entre otras, tenemos las siguientes:

\section{(i) Buscar redistribuir las actividades de una empresa o especializar las actividades}

\begin{tabular}{|c|c|c|c|c|c|}
\hline \multicolumn{6}{|c|}{ Cuadro No. 2} \\
\hline \multicolumn{3}{|l|}{ Activo } & \multicolumn{3}{|l|}{ Pasivo } \\
\hline \multirow{3}{*}{$\begin{array}{l}\text { Caja y bancos } \\
\text { Cuentas por cobrar } \\
\text { Maquinarias }\end{array}$} & $\mathrm{S} /$. & 50.00 & Cuentas por pagar & $\mathrm{S} /$. & 10.00 \\
\hline & $\mathrm{S} / \mathrm{s}$ & 10.00 & Remuneraciones por pagar & $\mathrm{S} /$. & 0.00 \\
\hline & $\mathrm{S} /$. & 10.00 & & & \\
\hline \multirow[t]{5}{*}{ Total activo } & $\mathrm{S} /$. & 70.00 & Total pasivo & $\mathrm{S} /$. & 0.00 \\
\hline & & & \multicolumn{3}{|l|}{ Patrimonio neto } \\
\hline & & & Capital social & $\mathrm{S} /$. & 60.00 \\
\hline & & & Resultados del ejercicio & $\mathrm{S} /$. & 0.00 \\
\hline & & & Total patrimonio neto & $\mathrm{S} /$. & 70.00 \\
\hline Total activo: & $\mathrm{S} /$. & 70.00 & Total pasivo + patrimonio: & $\mathrm{S} /$. & 70.00 \\
\hline
\end{tabular}


económicas en varias sociedades: En caso una empresa o varias ejecuten diversas actividades que, compatibles entre sí o no, generen un desorden administrativo y operativo, se optaría por una escisión para buscar organizarlas en el plano contable, de impuestos y de toma de decisiones entre los accionistas. También, el hecho de especializar las actividades en empresas distintas puede mejorar los controles de costos de producción, lo cual generaría mayores utilidades financieras para los accionistas o socios.

(ii) Reducción del pago de impuestos: Ya sea en el ejemplo utilizado en el capítulo II, o porque algunas empresas podrían encajar en regímenes especiales, sea por su tamaño, su rubro o la zona donde se encuentren (por ejemplo: CETICOS, Régimen de la Amazonía, entre otros), algunas actividades se podrían ver beneficiadas con un menor pago de impuestos, siempre y cuando encajen dentro de la hipótesis de incidencia tipificada por la norma.

(iii) Descentralización geográfica: Si bien al día de hoy los avances en la tecnología nos permite una comunicación bastante eficiente para el manejo de actividades empresariales, por motivos de organización se pueden escindir bloques patrimoniales con el objeto de contar con empresas nuevas y flexibilizar la estructura de cada una de ellas, como por ejemplo, nombrar directores y/o gerentes distintos en cada sociedad.

(iv) La falta de consenso permanente en la toma de decisiones en una sociedad: $\mathrm{Si}$ bien la regla general es que por la escisión los accionistas o socios de la sociedad es- cindida reciban acciones o participaciones de la sociedad beneficiaria; excepcionalmente, el segundo párrafo del artículo 368 de la LGS $^{5}$ permite que se disponga que uno (1) o más socios no reciban acciones o participaciones de alguno o algunas de las sociedades beneficiarias. Este supuesto puede suscitarse, sin embargo, si tomamos en cuenta que una de las instituciones principales al constituir una sociedad es la "affectio societatis", es decir, la voluntad común expresa de los socios de constituir una sociedad; y si ello durante la vida de la sociedad se rompe, sin duda desestabiliza a la sociedad, pudiendo llevarla al fracaso o a tener que tomar tal vez la decisión de una disolución y liquidación, pues ésta incluso puede ser voluntaria. La "affectio societatis" es un concepto de vital importancia en la vida de una sociedad $y$, al respecto, el doctor Oswaldo Hundskopf Exebio, refiriéndose a la sociedad anónima y a este concepto de la "affectio societatis", sostiene que "El pacto social viene a ser el acto jurídico en el que consta la manifestación expresa de la "affectio societatis" o la voluntad de los accionistas de constituirla", siendo en su opinión "el componente más importante del acto jurídico relativo a la constitución de una sociedad en general, y es precisamente lo que configura el carácter contractual de la constitución de una sociedad, siendo el estatuto social el reglamento interno de la sociedad y viene a ser un conjunto de normas de cumplimiento obligatorio, al cual se someten ésta y sus accionistas, constituyendo el marco dentro del cual deben desarrollarse los negocios y operaciones lícitas que configuran su objeto social".6. Es, pues, evidente que si esa voluntad común de los socios se rompe, las actividades de la sociedad se verán sin

5. Artículo 368.- Nuevas acciones o participaciones

Las nuevas acciones o participaciones que se emitan como consecuencia de la escisión pertenecen a los socios o accionistas de la sociedad escindida, quienes las reciben en la misma proporción en que participan en el capital de ésta, salvo pacto en contrario.

El pacto en contrario puede disponer que uno o más socios no reciban acciones o participaciones de alguna o algunas de las sociedades beneficiarias.

6. HUNDSKOPF EXEBIO, Oswaldo. Derecho Comercial. Temas societarios. Tomo V. Lima, Fondo de Desarrollo Editorial de la Universidad de Lima, 2004. p. 21. 
duda afectadas, pudiendo ésta fracasar o a poner fin a dichas actividades.

(v) Evitar incurrir en un sistema de concurso 0 de reestructuración: $\mathrm{O}$, incluso, el tener que disolver y liquidar una sociedad por el hecho de que alguna o algunas de las actividades que pueda realizar dentro de una economía de alcance carezcan de viabilidad.

\section{FORMAS DE LA ESCISIÓN}

Existen dos formas de escisión permitidas por la Ley, conocidas como escisión pura y simple o propia, y la escisión impropia o por segregación.

a) La escisión pura y simple o propia: $\mathrm{Se} d a$ cuando se divide la totalidad del patrimonio de la sociedad en dos o más bloques patrimoniales, y se transfieren a una sociedad o sociedades preexistentes o constituidas para el efecto o a ambas. Nótese que en este supuesto de división total del patrimonio la LGS establece que debe ser en dos (2) o más bloques patrimoniales y no en un solo bloque, pues si se admitiera este último caso, podría en nuestra opinión confundirse con la fusión, especialmente con la fusión por absorción. En esta modalidad de escisión se extingue la sociedad escindida, no siendo necesario que se declare su disolución previa, conforme lo establece expresamente el artículo 370 de la LGS.

\section{b) La escisión impropia o por segregación:} Se da cuando la sociedad transferente segrega o separa de su patrimonio uno (1) o más bloques patrimoniales y los transfiere a una sociedad o sociedades preexistentes o constituidas para el efecto o a ambas. En este caso la sociedad escindida subsiste, es decir, no se extingue, conservando su personalidad jurídica, y es por ello que la LGS admite que pueda transferirse uno (1) o más bloques patrimoniales, a diferencia de la escisión pura y simple que habla de la transferencia de dos (2) bloques patrimoniales como mínimo.

En esta modalidad, la sociedad escindida ajusta su capital en el monto correspondiente mediante una reducción de su capital social; para lo cual, tratándose de un caso de escisión regulado en la LGS, consideramos que no se observará ya, adicionalmente, los requisitos establecidos en la sección quinta de la misma LGS para la reducción del capital.

Precisamente, el doctor Oswaldo Hundskopf Exebio, concluye al tratar este punto que "En esta modalidad hay reducción de capital en la sociedad escindida (... $)^{\prime \prime 7}$. Sobre este tema de la reducción del capital existe un análisis interesante en el sentido que el capital de la sociedad escindida, aún cuando a través de la escisión se separa uno (1) o más bloques patrimoniales, podría verse incrementado si el bloque patrimonial transferido tuviera un valor neto negativo, que se daría si en el bloque se hubieran transferido más pasivos que activos (hecho que podría ocurrir en supuestos contables muy especiales). Esta posición se sustenta en que la LGS, en el numeral 2 de su artículo $367^{8}$, señala que la sociedad escindida ajusta su capital en el monto correspondiente, lo que para dicho análisis significa que po-

7. HUNDSKOPF EXEBIO, Oswaldo. Curso de formación: Temas de Derecho Empresarial y Comercial: "Curso de Sociedades". Programa para la Formación y Ascenso de Magistrados de la Academia de la Magistratura. Lima, 2004. p. 105.

8. Artículo 367.- Concepto y formas de escisión

Por la escisión una sociedad fracciona su patrimonio en dos o más bloques para transferirlos íntegramente a otras sociedades o para conservar uno de ellos, cumpliendo los requisitos y las formalidades prescritas por esta ley. Puede adoptar alguna de las siguientes formas:

La división de la totalidad del patrimonio de una sociedad en dos o más bloques patrimoniales, que son transferidos a nuevas sociedades o absorbidos por sociedades ya existentes o ambas cosas a la vez. Esta forma de escisión produce la extinción de la sociedad escindida; 0 , 
dría ser disminuyéndolo o aumentándolo o no variándolo, en la medida en que el bloque patrimonial transferido tuviera un valor cero o neutro.

En nuestro concepto, ciñéndonos a una interpretación literal y sistemática sólo de las normas societarias que regulan la escisión, sobretodo teniendo en cuenta el primer párrafo del artículo 368 de la LGS, en tanto se transfiere en una escisión por segregación un bloque patrimonial que se fracciona del patrimonio social, ocurriría una reducción del capital de la sociedad escindida, aún cuando la posición explicada en el párrafo anterior pueda ser respetable dentro de un punto de vista contable.

Por ello, consideramos que como consecuencia de una escisión por segregación o impropia, a través de la transferencia del bloque patrimonial se genera, de lo que se desprende de la interpretación de las normas del derecho societario, una reducción del capital de la sociedad escindida; $y$, sus accionistas o socios reciben, como contraprestación, acciones o participaciones que se emiten por consiguiente, tal como lo establece el primer párrafo del citado artículo 368 de la LGS.

Precisamente, las nuevas acciones o participaciones que se emiten como consecuencia de la escisión a través de cualquiera de las dos (2) modalidades de escisión explicadas, les corresponderá a los accionistas o socios de la sociedad escindida, quienes las reciben en la misma proporción en que participan o participaron en el capital social de ésta, siendo por supuesto de vital importancia establecer la relación de canje para determinar las acciones o participaciones que recibirán los accionistas o socios de la sociedad escindida de la sociedad beneficiaria. La LGS en el segundo párrafo de su artículo 368, permite que por pactos se regule el derecho de los accionistas o socios a recibir las acciones o participaciones, siendo factible que, como una excepción a la regla, por dicho pacto uno o más socios no reciban acciones o participaciones de alguna o algunas de las sociedades beneficiarias.

\section{CONCEPTO DE BLOQUE PATRIMONIAL Y SU INTEGRACIÓN PATRIMONIAL}

Nuestra LGS tiene el acierto de no sólo considerar una escisión como una división total o segregación, según las modalidades admitidas por ésta, del patrimonio de la sociedad escindente, sino además precisa que esa división total o segregación, según corresponda, debe hacerse en bloques patrimoniales, los mismos que para los efectos son definidos en el artículo 369 de la propia LGS.

Es así que se entiende por bloque patrimonial:

1. Un activo o un conjunto de activos de la sociedad escindida, pudiendo de esta manera darse los siguientes supuestos:

a) Un activo de la sociedad escindida, prescindiendo de su pasivo;

b) Un conjunto de activos de la sociedad escindida, prescindiendo también de sus pasivos;

2. El conjunto de uno o más activos y uno o más pasivos de la sociedad escindida, pudiendo darse los siguientes supuestos:

a) Un activo y un pasivo de la sociedad escindida;

b) Un conjunto de activos y un pasivo de la sociedad escindida;

c) Un activo y un conjunto de pasivos de la sociedad escindida; $y$,

d) Un conjunto de activos y un conjunto de pasivos de la sociedad escindida.

El valor de los activos y los pasivos determinará el valor neto final del bloque patrimo-

La segregación de uno o más bloques patrimoniales de una sociedad que no se extingue y que los transfiere a una o más sociedades nuevas, o son absorbidos por sociedades existentes o ambas cosas a la vez. La sociedad escindida ajusta su capital en el monto correspondiente.

En ambos casos los socios o accionistas de las sociedades escindidas reciben acciones o participaciones como accionistas o socios de las nuevas sociedades o sociedades absorbentes, en su caso. 
nial. El bloque patrimonial conformado sólo por pasivos no está regulado en el citado artículo 369, como es de verse, partiendo de la base que lo que se busca es que el bloque patrimonial como tal, debe ser pasible de ser valorizado económicamente para que se dé cumplimiento a lo establecido en el primer párrafo del artículo 368 de la LGS. En ese sentido, el bloque patrimonial conformado sólo por pasivos, no debiera tener, en nuestra opinión, asidero en nuestro derecho positivo.

3. Un fondo empresarial, que en nuestra legislación no tiene una definición legal, pero doctrinariamente es definido como el conjunto de bienes y derechos organizados por personas naturales o jurídicas para el desarrollo de una actividad empresarial, siendo susceptible de valoración económica. Así, los doctores Luz Israel Llave y Alfredo Filomeno Ramírez señalan que "son cualidades que inciden en el valor del fondo empresarial, entre otros, los siguientes: la clientela, la ubicación estratégica del local donde se lleva a cabo la actividad empresarial; la buena calidad de la materias primas y mercaderías; el prestigio de los signos distintivos; y la eficiente organización de los elementos del fondo empresarial"' Concordamos con la apreciación de los distinguidos colegas especialistas en el tema, pero particularmente pensamos que lo que más distingue un fondo empresarial dentro de lo enunciado por ellos es, sobretodo, la eficiente organización de los elementos del fondo empresarial, pues precisamente esa eficiente organización hace que una sociedad especializada en su actividad sea una unidad de negocio productiva, sea en la producción de bienes o en la prestación de servicios. Sin embargo, no debe pen- sarse que el fondo empresarial transferido como bloque patrimonial implique necesariamente una unidad de negocio o unidad económica para la sociedad beneficiaria, sino lo trascendental es que se convierta en ella una vez recibido éste por esta última. En ese sentido coincidimos con el doctor Enrique Elías Laroza cuando señala que "Lo importante en una escisión no es que el bloque que se transmite sea, por sí mismo, una unidad económica o empresarial, sino que se convierta en ella en el seno de la sociedad beneficiaria que lo recibe ${ }^{110}$.

En cuanto a la transferencia del bloque o bloques patrimoniales a la o las sociedades beneficiarias cuando son sociedades preexistentes, usualmente originan en estas últimas un aumento de su capital social. Precisamente el doctor Oswaldo Hundskopf Exebio precisa, dentro de la regla general enunciada, que "cuando concurren sociedades preexistentes, por la escisión se genera un aumento de capital en las sociedades que absorben los bloques patrimoniales"11.

No obstante, pueden darse casos de excepción de la regla general que no necesariamente originan un aumento del capital social de la sociedad preexistente que recibe el bloque patrimonial. Estos pueden ser:

1. Cuando la sociedad beneficiaria es titular de todas las acciones o participaciones de la sociedad escindida.

2. Cuando la sociedad beneficiaria es titular de parte de las acciones o participaciones de la sociedad escindida. El aumento se producirá con relación a los restantes accionistas o socios de la sociedad escindida, distintos a la sociedad beneficiaria en su calidad de accionista en la sociedad escindida.

9. ISRAEL LLAVE, Luz y FILOMENO RAMÍREZ, Alfredo. La fusión y la escisión en la nueva Ley General de Sociedades, algunas aproximaciones. En:Tratado de Derecho Mercantil, Tomo I. Lima, Gaceta Jurídica en co-edición con el Instituto Peruano de Derecho Mercantil, 2003. p. 1188.

10. ELIAS LAROZA, Enrique. Derecho Societario Peruano. La Ley General de Sociedades del Perú. Obra completa. Trujillo, Editorial Normas Legales, 2003. p. 799.

11. HUNDSKOPF EXEBIO, Oswaldo. Curso de Formación: Temas de Derecho Empresarial y Comercial: "Curso de Sociedades". Programa para la Formación y Ascenso de Magistrados de la Academia de la Magistratura. Lima, 2004. p. 106. 
3. Cuando la sociedad escindida sea titular de acciones de la sociedad beneficiaria y dichas acciones forman parte o conforman totalmente el bloque patrimonial a transferirse.

4. Cuando la sociedad beneficiaria tiene acciones en cartera.

5. Cuando la sociedad beneficiaria decide disminuir el valor nominal de las acciones para aumentar el número de acciones y distribuirlas a los accionistas de la sociedad escindida.

Finalmente, el artículo 124 del Reglamento del Registro de Sociedades habla del valor neto positivo y del valor neto negativo al referirse al valor neto del bloque patrimonial, aplicando un criterio contable. En este sentido, y dentro del supuesto de dicho artículo 124, si el valor neto del bloque patrimonial fuera negativo, tampoco generará dentro de los supuestos antes enunciados un aumento de capital en la sociedad beneficiaria preexistente.

Los seis (6) supuestos de excepción enunciados, incluyendo el del párrafo que antecede, se infieren también del numeral 7 del artículo 372 de la LGS, que alude al proyecto de escisión, que señala que el proyecto debe expresar "(...) la variación del monto del capital de la sociedado las sociedades beneficiarias, si lo hubiere".

\section{IMPLICANCIAS TRIBUTARIAS DE LA ESCISIÓN}

\section{Del Impuesto a la Renta}

Entre los aspectos tributarios más importantes en una operación de escisión, se puede apreciar en el artículo 104 de la Ley del Impuesto a la Renta que existen tres (3) regímenes por los que pueden optar las partes intervinientes:

a. Revaluación voluntaria con efectos tributarios: Se puede acordar otorgar a los activos un mayor valor al que tienen en la contabilidad de la sociedad transferente, lo cual generaría que los bienes transferidos tengan un mayor costo computable como "activo" y, por tanto, una mayor base sobre la cual depreciarlos mensual o anualmente. Sin embargo, este mayor valor otorgado como "activo" generará un "ingreso" en los resultados de la sociedad, lo cual, en términos gruesos, generaría un pago del Impuesto a la Renta proveniente de dicho ingreso por la revaluación.

\section{b. Revaluación voluntaria sin efectos} tributarios: En este supuesto se pueden revaluar los activos y el ingreso generado no estará gravado con Impuesto a la Renta, pero siempre y cuando este ingreso no se distribuya a favor de sus accionistas. Además, el mayor valor otorgado a los bienes solamente tendrá un efecto meramente contable-financiero, mas no tributario, por lo que no se incrementará el costo computable ni una mayor base para depreciar tributariamente los bienes.

c. Sin revaluación voluntaria: En este supuesto no se acuerda ninguna revaluación de activos, por lo que los bienes transferidos tendrán el mismo valor en libros que tenían en poder de la transferente (en este caso, escindida), sin que se genere una ganancia sobre la cual determinar Impuesto a la Renta alguno.

Tampoco se podrán imputar las pérdidas tributarias de la sociedad escindida a la empresa beneficiaria, conforme lo dispone el artículo 106 de la Ley del Impuesto a la Renta, con la finalidad de evitar estrategias como la de "inflar" una sociedad con pérdidas tributarias para, posteriormente, transferirlas a una nueva sociedad o una ya existente, desvirtuando con ello el verdadero propósito de una escisión.

\section{Del Impuesto General de las Ventas (IGV)}

Respecto al IGV, entre sus aspectos más importantes podemos destacar que si bien este Impuesto afecta a la venta en el país de bienes muebles, el inciso c) del artículo 2 de la Ley del IGV dispone expresamente que la transferencia de bienes que se realice como consecuencia de la reorganización de empresas (incluyendo a la escisión) no está gravada con el Impuesto.

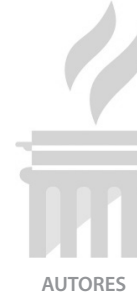

\section{.}


Dicho en otras palabras, no se produce un IGV por pagar ni se genera derecho a utilizar crédito fiscal alguno por las transferencias de los bienes muebles de una sociedad a otra, con motivo de una escisión.

Adicionalmente, se podrá transferir a la nueva empresa beneficiaria el crédito fiscal existente a la fecha de la escisión, de conformidad con el cuarto párrafo del artículo 24 de la Ley del IGV, siempre y cuando se respeten las formalidades precisadas en el numeral 12 del artículo 6 de su Reglamento.

\section{OTRAS CONSIDERACIONES IMPORTANTES SOBRE LA ESCISIÓN}

\section{El procedimiento de escisión}

El procedimiento de escisión a "grosso modo" se inicia con la aprobación del Directorio de cada sociedad participante, con el voto favorable de la mayoría absoluta de miembros, del texto del proyecto de escisión. Respecto al contenido del proyecto de escisión, la LGS lo establece en su artículo 372.

En dicho proyecto de escisión, al igual como ocurre en la fusión, se señala una fecha de entrada en vigencia de la escisión, la cual como parte integrante del proyecto de escisión, deberá ser aprobado finalmente en la Junta General de cada sociedad participante que se celebre con tal fin; siendo verdaderamente de gran utilidad y novedoso en la LGS el que se pueda señalar la entrada en vigencia de la escisión sin que se haya inscrito aún el acuerdo de escisión en el Registro correspondiente para que surta efectos, aun cuando la inscripción registral del acuerdo deba obtenerse necesariamente a posteriori como manda la Ley.

Aprobado el proyecto de escisión por el Directorio de las sociedades participantes, éstos deben abstenerse de realizar o ejecutar cualquier acto o contrato que pueda comprometer la aprobación del proyecto o alterar significativamente la relación de canje de las acciones o participaciones hasta la fecha de realización de la Junta General de cada sociedad participante convocada para pronunciarse sobre la escisión.

En caso no hubiera Directorio, el proyecto será aprobado por la mayoría absoluta de las personas encargadas de la administración de la sociedad.

De otro lado, entre el aviso de convocatoria para tratar la aprobación de la escisión y la realización de la junta por cada sociedad participante, deben mediar diez (10) días. Por su parte, desde la publicación del aviso de convocatoria debe ponerse a disposición de los accionistas, socios, obligacionistas y demás titulares de derechos de crédito o títulos especiales, en su domicilio social, los documentos detallados en el artículo 375 de la LGS, entre ellos el proyecto de escisión y estados financieros auditados de las sociedades participantes. Aprobada la escisión por la Junta General de cada sociedad participante, se aprueba también una fecha común de entrada en vigencia de la escisión, consignada en el proyecto de escisión, como hemos explicado, fecha a partir de la cual las sociedades beneficiarias asumen automáticamente las operaciones, derechos y obligaciones de los bloques patrimoniales escindidos y cesan con respecto a ellos las operaciones, derechos y obligaciones de la o las sociedades escindidas, ya sea que se extingan o no, según las formas de escisión antes comentadas y que la LGS admite.

Sin perjuicio de la inmediata entrada en vigencia, la escisión queda supeditada, como hemos dicho, a la inscripción de la escritura pública en el Registro, en las partidas registrales de cada sociedad participante. La inscripción de la escisión produce la extinción de la sociedad escindida, cuando éste fuera el caso. Por lo demás, cada sociedad participante cierra su respectivo balance de escisión al día anterior al fijado para la vigencia de la escisión, con excepción de las nuevas sociedades que se constituyen por razón de la escisión, las que deben formular un balance de apertura al día fijado para la vigencia de la escisión.

Los acuerdos de escisión aprobados en junta general se publican por tres (3) veces con intervalos de cinco (5) días y desde la fecha de la última publicación los socios de las sociedades participantes pueden ejercer dentro del plazo de diez (10) días su derecho de separación, así como los acreedores de las sociedades participantes tienen el plazo de treinta (30) 
días para ejercitar su derecho de oposición al acuerdo. Transcurridos los treinta (30) días sin que hubiere habido oposición alguna, se eleva a escritura pública los acuerdos de escisión, observando los requisitos que prescribe el artículo 382 de la Ley, para su posterior inscripción en el Registro correspondiente. Si hubiera oposición se suspende el acuerdo hasta que se paguen los créditos o éstos sean debidamente garantizados. La oposición se tramita como proceso sumarísimo.

De otro lado, aunque no se ciñe estrictamente al tema que estamos tratando, sólo en cuanto a la escisión se refiere estimamos importante destacar que como otras formas de reorganización, el artículo 392 de la LGS contempla como tales las escisiones múltiples, en las que intervienen dos (2) o más sociedades escindidas; escisiones múltiples combinadas, en las cuales los bloques patrimoniales de las distintas sociedades escindidas son recibidas, en forma combinada, por diferentes sociedades, beneficiarias y las propias escindidas; escisiones combinadas con fusiones, entre las mismas sociedades participantes; escisiones y fusiones combinadas entre múltiples sociedades; $y$, cualquier otra operación en que se combinen transformaciones, fusiones y escisiones.

Asimismo, el artículo 405 de la LGS regula los efectos de una escisión (también de la fusión) cuando una sociedad que se escinde y ha sido constituida en el país, tiene una sucursal en el Perú, señalando que la sociedad incorporante asume la sucursal de la sociedad que se escinde, salvo indicación en contrario. En este caso, para el cambio de sociedad titular de la sucursal, se requerirá presentar la certificación expedida por el Registro correspondiente de haber quedado inscrita la escisión en las partidas correspondientes a las sociedades principales participantes.

Del mismo modo, el artículo 406 de la LGS regula los efectos de la escisión (también de la fusión) cuando sociedades extranjeras con sucursal en el Perú participen en una escisión, señalando que para el cambio de sociedad titular de la sucursal, originada en la escisión de la sociedad principal constituida en el extranjero, el Registro correspondiente en el Perú requerirá la presentación de la documentación que acredite que la escisión ha entrado en vigencia en el lugar, el nombre, lugar de constitución y domicilio de la sociedad beneficiaria del bloque patrimonial, y que ella puede tener sucursales en otro país.

\section{Diferencias de la escisión con otras instituciones jurídicas reguladas en la Ley}

(i) La transformación es un cambio de la naturaleza jurídica de una sociedad preexistente a otro tipo de sociedad contemplada en la Ley, sin perder su personalidad jurídica.

(ii) A diferencia de lo que ocurre en la disolución, liquidación y extinción de una sociedad, la sociedad escindida por división total se disuelve sin liquidarse y en el caso de la sociedad escindida por segregación no se disuelve, manteniendo incluso su personalidad jurídica.

(iii) En la fusión se incorpora todo el patrimonio a una sociedad a que se destina, mientras que en la escisión se incorpora en bloques patrimoniales parte del patrimonio de la sociedad escindida a la o las sociedades beneficiarias o la totalidad de éste, en la forma que la Ley establece.

(iv) En la reorganización simple una sociedad segrega uno (1) o más bloques patrimoniales y los aporta a una (1) o más sociedades nuevas o preexistentes, pero a diferencia de la escisión, es la sociedad aportante y no sus socios, la que recibe a cambio y conserva en su activo las acciones o participaciones correspondientes a dichos aportes, no teniendo, de otro lado, que observar el procedimiento de escisión antes comentado.

Antes de concluir, queremos decir que dentro de lo antes comentado sobre la escisión y teniendo en cuenta que las sociedades deben hoy por hoy adecuarse a las condiciones de mercado y ser competitivas, la figura jurídica de la escisión resulta de suma utilidad, habiendo tenido la Ley General de Sociedades vigente (Ley 26887), el gran acierto de regularla por primera vez dentro de nuestro ordenamiento jurídico. 